\title{
Derailment risk and dynamics of railway vehicles in curved tracks: Analysis of the effect of failed fasteners
}

\author{
Silvia Morales-Ivorra ${ }^{1} \cdot$ Julia Irene Real $^{1} \cdot$ César Hernández $^{1} \cdot$ Laura Montalbán $^{1}$
}

Received: 31 March 2015/Revised: 18 December 2015/Accepted: 21 December 2015/Published online: 30 January 2016

(C) The Author(s) 2016. This article is published with open access at Springerlink.com

\begin{abstract}
The effect of the fastener's failure in a railway track on the dynamic forces produced in the wheel-rail contact is studied using the simulation software VAMPIRE to assess the derailment risk of two different vehicles in two curves with distinct characteristics. First, a 3D-FEM model of a real track is constructed, paying special attention to fasteners, and calibrated with displacement data obtained experimentally during a train passage. This numerical model is subsequently used to determine the track vertical and lateral stiffness. This study evidences that although the track can practically lose its lateral stiffness as a consequence of the failure of 7 consecutive fasteners, the vehicle stability would not be necessarily compromised in the flawed zone. Moreover, the results reveal that the uncompensated acceleration and the distance along which the fasteners are failed play an important role in the dynamic behavior of the vehicle-track system, influencing strongly the risk of derailment.
\end{abstract}

Keywords Railway dynamics · Fasteners - Derailment . Curved track

\section{Introduction}

Any railway manager must fulfill minimum requirements of comfort and safety. In this sense, curved layouts require special attention since they have a great influence on the dynamic behavior of the vehicle-track system. Correct

Silvia Morales-Ivorra

silmoiv@cam.upv.es

1 University Institute for Multidisciplinary Mathematics, Polytechnic University of Valencia, 46022 Valencia, Spain designs as well as an effective maintenance plan are key aspects to prevent and correct the deterioration of the vehicle and the track.

There are many complex track-vehicle interaction models designed for curved tracks as stated in [1]. For instance, in [2] a half-car on a ballasted track is modeled in detail; in this model, the different masses of the vehicletrack system are interconnected via springs and dampers. The versatility of this model is so high that it has been adapted to predict rail wear in curves [3], to calculate the plastic deformation in welds located in curved stretches [4], and to analyze the development and propagation of corrugation in curves [5]. Other approaches for the study of track-vehicle interaction can be found in [6] for the study of dynamic non-linearities produced in curves and in [7] for the analysis of the lateral stability of a freight train in a curve.

Apart from the above-mentioned multi-body methods, there are commercial programs that permit the implementation and resolution of complex vehicle-track dynamic systems with many degrees of freedom. These software products are suitable to study the complex dynamic phenomena arising in curved tracks. For example, SIMPACK is used in [8] and [9] to study, respectively, the vibrations produced in a vehicle running on a curve and the influence of the curve parameters on the wear of the wheel-rail contact. Furthermore, the software of dynamic simulation VAMPIRE is used in [10] to study the wear produced in the elements of a turnout by the vehicle passage.

Vehicle-track dynamics in curves are closely related to derailments [11]. For this reason, in [12] track and vehicle conditions are related with the proclivity to derailment in curves of small radii. This study revealed that the derailment coefficient decreases as the curve radius increases. Another similar research was conducted in [13] using the 
simulation software SIMPACK. A deeper analysis about the influence of the curve parameters and vehicle speed on derailment was presented in [14], employing the commercial software ADAMS/Rail. Derailment in a high-radius curve $(7,000 \mathrm{~m})$ including the effect of the fastener failure is analyzed in [15]; this study demonstrated that in this high-radius concrete curve, the stability of a high speed train is not compromised if the number of failed fasteners is lower than 15.

The relationship between flawed fasteners and derailment risk has been also studied in [16] in a tangent track using a coupled vehicle/track model. The results show the strong influence of the disabled fasteners on the derailment coefficient and on the track widening, which also increases the derailment risk. The research [17], conducted in slab tracks, concludes that failed fasteners cause increased displacements on the rail and the slab which become greater with increasing vehicle speed. In [18], the derailment risk in a curved track is assessed considering failures in the track supports, demonstrating their great influence on the running safety; the vehicle and the track infrastructure are modeled as a multi-body system, while the rails are modeled as Timoshenko beams resting on discrete supports. The importance of the lateral dynamics on vehicle stability has prompted the development of innovative elements, such as frictional sleepers [19] to increase the lateral resistance of railway tracks, and of new monitoring techniques to maintain the fasteners in perfect condition [20].

The present study aims to continue in this research stem to evaluate the dynamic behavior of the vehicle in curved tracks where fasteners have failed. However, two different vehicles will be considered in this case (passengers and freight), with their respective speeds, and two curves of different radii. The vehicle-track model will be implemented in VAMPIRE, while the track vertical and lateral stiffness are calculated using an auxiliary FEM model calibrated from experimental data. The objective of this research is to present a method to reproduce the track vertical and lateral stiffness in a FEM model and study how a fastener failure influences the dynamic stability in two different curves on which two different vehicles circulate with different speeds and static loads.

\section{Experimental campaign}

A ballasted track stretch with Iberian gauge $(1,668 \mathrm{~mm})$, UIC-60 rails, and monoblock prestressed concrete sleepers AI-04-EA was monitored during the experimental campaign. The railpad, with a thickness of $5 \mathrm{~mm}$, has a vertical stiffness of $300 \mathrm{kN} / \mathrm{mm}$, and the rail is attached to the sleeper with Vossloh VM fasteners, generally used in the Spanish ballasted tracks. Each fastener consists of a clip

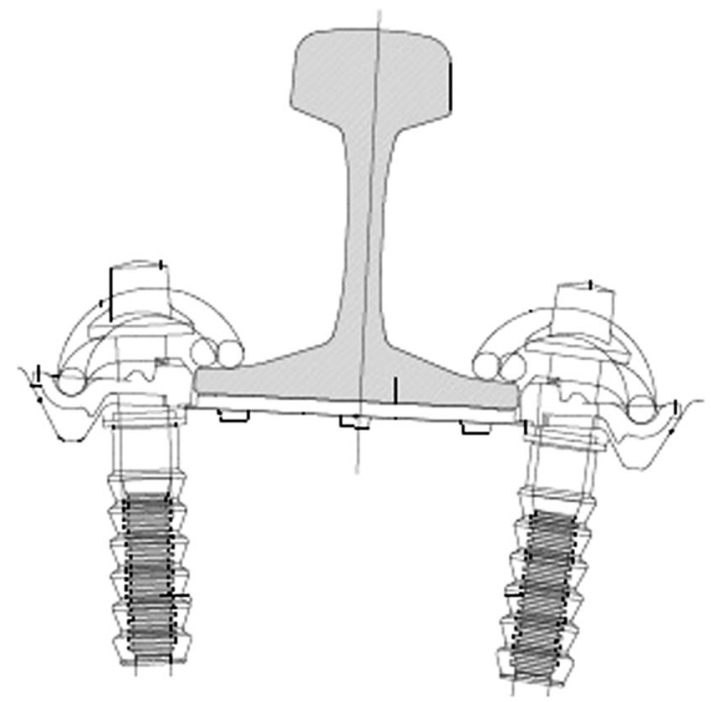

Fig. 1 Vossloh VM fastener

SKL-1, a sheath V2, an angled mounting plate A2, a T2 screw with a locking washer, and an elastic plate PAE-2. The fastener sketch is depicted in Fig. 1.

The track stretch was instrumented with displacement transducers in the rail and with rod extensometers located between the granular layers (ballast and subballast). Therefore, the total deflection of the infrastructure caused by the train passages can be calculated as the sum of these relative displacements. In Table 1, the experimental results corresponding to the passage of a locomotive Renfe S-252 at $160 \mathrm{~km} / \mathrm{h}$ are shown.

The interface between the subballast and the platform was also equipped with pressure cells. These cells registered the stresses induced in this zone, allowing the calculation of the track vertical stiffness, which resulted to be $90 \mathrm{kN} / \mathrm{mm}$. Moreover, during the data acquisition campaign, the tightening torque of the fastener screws was revised, obtaining an average value of $220 \mathrm{Nm}$. Experimental data will be the fundamental support to construct a numerical model able to represent accurately the real track behavior.

\section{Models}

\subsection{Model of the studied track}

The objective of the FEM model is to calculate the values of track vertical and lateral stiffness in different scenarios

Table 1 Deflections produced in the infrastructure by the locomotive passage

\begin{tabular}{lll}
\hline Relative strains $(\mathrm{mm})$ & Total deflection $(\mathrm{mm})$ \\
\hline Rail & Granular layers & \\
\hline 0.479 & 0.765 & 1.244 \\
\hline
\end{tabular}




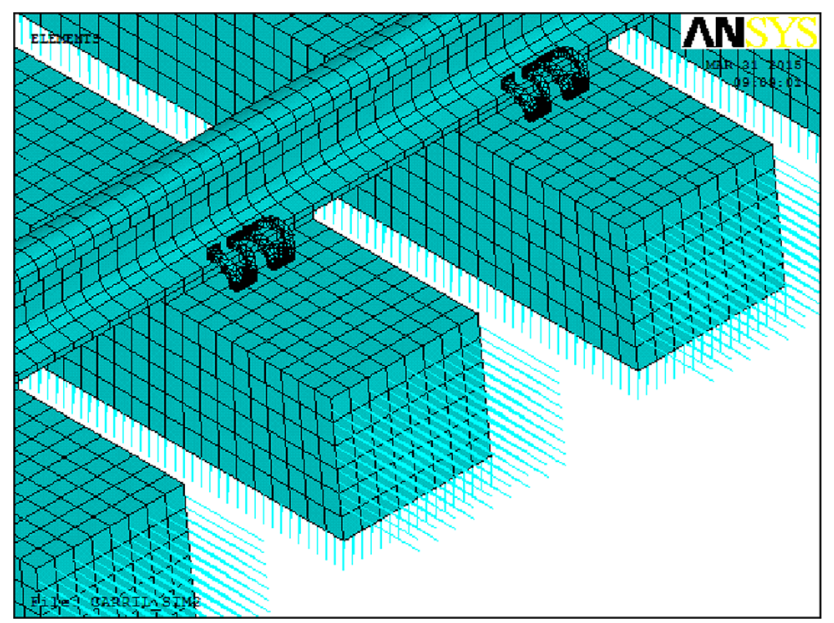

Fig. 2 FEM model of the track superstructure with springs supporting the sleeper

in which fasteners fail. For this reason, a simplified model is constructed to represent in detail the upper part of the track superstructure, including the rails, the fasteners, and the sleepers which rest on elastic supports that simulate the granular layers (see Fig. 2). These elastic supports consist of spring elements attached to the sleepers and oriented in the vertical and lateral direction.

The cross sections of the UIC-60 rail, the AI-04-EA sleeper, and the railpad sections have been drawn in detail using a CAD software and then imported to the FEM software ANSYS LS-DYNA V.14. These sections are extruded, generating the real elements, which are divided in hexahedral elements SOLID45 with a maximum side of $0.04 \mathrm{~m}$. The mechanical properties (Young modulus, E; Poisson coefficient, $v$; and density, $\rho$ ) of the track elements are summarized in Table 2 . Regarding the boundary conditions, the length of the model is $9 \mathrm{~m}$, long enough to avoid the influence of the extreme boundaries on the static results, which are always calculated in the center of the model. Rotations and longitudinal movements of the rail extremes are constrained in the model boundaries, while the sleeper displacements are conditioned by the spring elements that account for the elastic support.

As observed in Fig. 3, in order to model the fastener, the clip has been represented in detail and the screw effect has been represented by compressive forces acting on each clip. The lateral and plan view of the fastener is imported in

Table 2 Mechanical properties of the track superstructure elements

\begin{tabular}{lllr}
\hline Element & $E(\mathrm{MPa})$ & $v$ & $\rho\left(\mathrm{kg} / \mathrm{m}^{3}\right)$ \\
\hline Rail & $2.10 \times 10^{4}$ & 0.3 & 7,830 \\
Railpad & 119 & 0.49 & 900 \\
Sleeper & $2.70 \times 10^{4}$ & 0.35 & 2,400 \\
Fastener & $2.10 \times 10^{4}$ & 0.3 & 7,830 \\
\hline
\end{tabular}

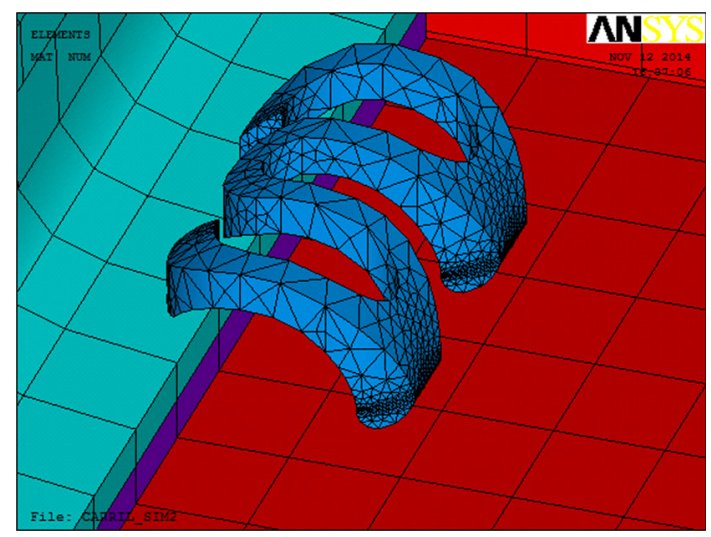

Fig. 3 Detail of the FEM model of the clip

a CAD file to construct the model in ANSYS. In this case, the element used is also the SOLID45 but the mesh is selfadapted by the program in order to adapt the mesh to the curved contours of the fastener in an efficient manner that provides numerical convergence. This force has been calculated from the tightening torque of the screws measured in the experimental campaign. Furthermore, the condition of strain compatibility has been imposed in the nodes located in the clip-sleeper and clip-rail contact zones.

The crucial step to calibrate the model is to determine the stiffness of the springs attached to the sleepers. From the experimental campaign, it is known that the track vertical stiffness is $90 \mathrm{kN} / \mathrm{mm}$. However, assigning directly this stiffness to the springs in the model is incorrect, since it includes the contribution of elements such as the sleeper, the fastener, and the rail which are already represented in the FEM model. Instead, a linear behavior is assumed to estimate the force $F$ transmitted by the wheel of the locomotive Renfe $S$-252 to the rail head in the monitored section from Eq. (1):

$F=k_{\mathrm{v}} \delta$,

where $k_{\mathrm{v}}$ is the vertical track stiffness $(90 \mathrm{kN} / \mathrm{mm})$ and $\delta$ is the deflection produced according to Table $1(1.244 \mathrm{~mm})$. Therefore, the transmitted force is $F=112 \mathrm{kN}$.

On the one hand, knowing the vertical force acting on the wheel-rail contact, it is possible to calculate the vertical stiffness of the springs that support the sleepers in the FEM model. To do so, a force $F=112 \mathrm{kN}$ is introduced in the model and, subsequently, the deflections in the rail head are calculated by varying the stiffness of the springs. When a deflection result equal to the experimentally measured $1.244 \mathrm{~mm}$ is reached, it is considered that the model is calibrated and that the vertical stiffness of the springs at that moment is adequate to reproduce the real behavior of the system. In this case, the stiffness of the vertical springs when all the fasteners are in perfect conditions is $k_{\mathrm{v}_{-} \text {spring }}=$ $2.3962 \times 10^{-2} \mathrm{kN} / \mathrm{mm}$. 


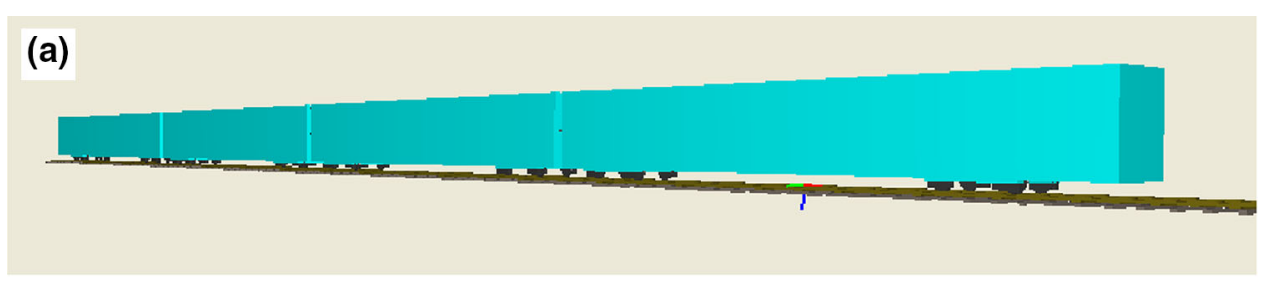

(b)

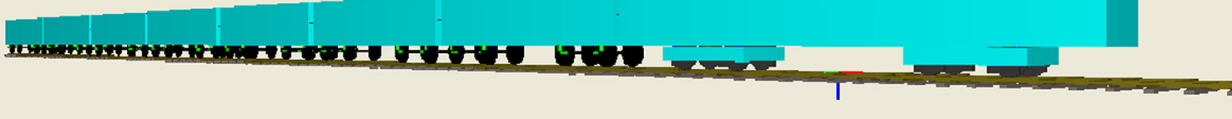

Fig. 4 Model of the vehicles in VAMPIRE. a Passenger train. b Freight train

On the other hand, obtaining the track lateral stiffness experimentally requires very complex and costly tests [21] that were not done during the experimental campaign. Consequently, the authors have searched in the existing literature experimental values of this parameter already used to validate other models. The Ref. [22] states that in a ballasted track with UIC-60 rails, middle-stiffness railpads and monoblock prestressed concrete sleepers, as in the studied case, the lateral stiffness of the ballast layer is $k_{\mathrm{h} \_ \text {ballast }}=110 \mathrm{kN} / \mathrm{mm}$ per linear meter. It should be highlighted that this value for lateral stiffness is given per unit of length. This figure can be assimilated to the equivalent stiffness of all the springs located in the lateral direction in the FEM model. Considering that there are 1,695 parallel springs in the sleepers' lateral sides and that the model length is $L=9 \mathrm{~m}$, the lateral stiffness of each spring can be calculated by Eq. (2):

$k_{\mathrm{h}_{-} \text {spring }}=k_{\mathrm{h}_{-} \text {ballast }} \frac{L}{N}=0.584071 \mathrm{kN} / \mathrm{mm}$,

where $N$ is the number springs.

Apart from the lateral stability provided by the ballast layer and the fastener, there are friction forces at the railrailpad and sleeper-railpad surfaces that oppose the lateral displacements. These friction forces depend mainly on the mechanical properties of the railpads' material [23] and therefore are implicitly considered in the studied model.
The result of the calibration is a finite element model able to reproduce the real behavior of the track. This model is used in Sect. 4 to calculate the vertical and lateral track stiffness in different scenarios with failed fasteners.

\subsection{Track-vehicle interaction model}

Track-vehicle interaction has been analyzed using the dynamic simulation package VAMPIRE. In this program, two of the vehicles that normally run in this line have been represented: the passenger vehicle Renfe $S-120$ and a convoy of well cars carrying containers and hauled by a locomotive Renfe S-253 (see Fig. 4). Both vehicles have been represented as dynamic systems of three masses (unsprung, semi-sprung, and sprung) connected by springdamper elements that simulate the contact with the rail and the vehicle suspensions. The estimated values of the vehicle dynamic systems studied are summarized in Table 3.

\section{Calculation of the track stiffness in different scenarios of fastener failure}

In the model described in Sect. 3, fasteners will be steadily removed to calculate the variations produced on the vertical stiffness $k_{\mathrm{v}}$ and on the lateral stiffness $k_{\mathrm{h}}$ when the

Table 3 Inputs of the vehicle-track dynamic interaction model in VAMPIRE

\begin{tabular}{cllllllll}
\hline $\begin{array}{l}\text { Vehicle } \\
\text { type }\end{array}$ & Car type & $\begin{array}{l}\text { Wheelset } \\
\text { mass }(\mathrm{kg})\end{array}$ & $\begin{array}{l}\text { Bogie } \\
\text { mass }(\mathrm{kg})\end{array}$ & $\begin{array}{l}\text { Carbody } \\
\text { mass }(\mathrm{kg})\end{array}$ & $\begin{array}{l}\text { Primary } \\
\text { stiffness (N/m) }\end{array}$ & $\begin{array}{l}\text { Primary } \\
\text { damping (Ns/m) }\end{array}$ & $\begin{array}{l}\text { Secondary } \\
\text { stiffness (N/m) }\end{array}$ & $\begin{array}{l}\text { Secondary } \\
\text { damping (Ns/m) }\end{array}$ \\
\hline Renfe & Locomotive & 1,600 & 4,000 & 48,000 & $1.69 \times 10^{6}$ & $5.20 \times 10^{4}$ & $2.38 \times 10^{6}$ & $2.00 \times 10^{5}$ \\
S-120 & Carriage & 1,600 & 4,000 & 44,500 & $1.69 \times 10^{6}$ & $5.20 \times 10^{4}$ & $2.38 \times 10^{6}$ & $2.00 \times 10^{5}$ \\
Renfe & Locomotive & 1,800 & 5,000 & 40,000 & $1.20 \times 10^{6}$ & $1.50 \times 10^{4}$ & $3.00 \times 10^{5}$ & $1.00 \times 10^{4}$ \\
S-253 & $\begin{array}{l}\text { Freight } \\
\text { wagon }\end{array}$ & 1,800 & 2,100 & 32,000 & $2.60 \times 10^{6}$ & - & - & - \\
\hline
\end{tabular}




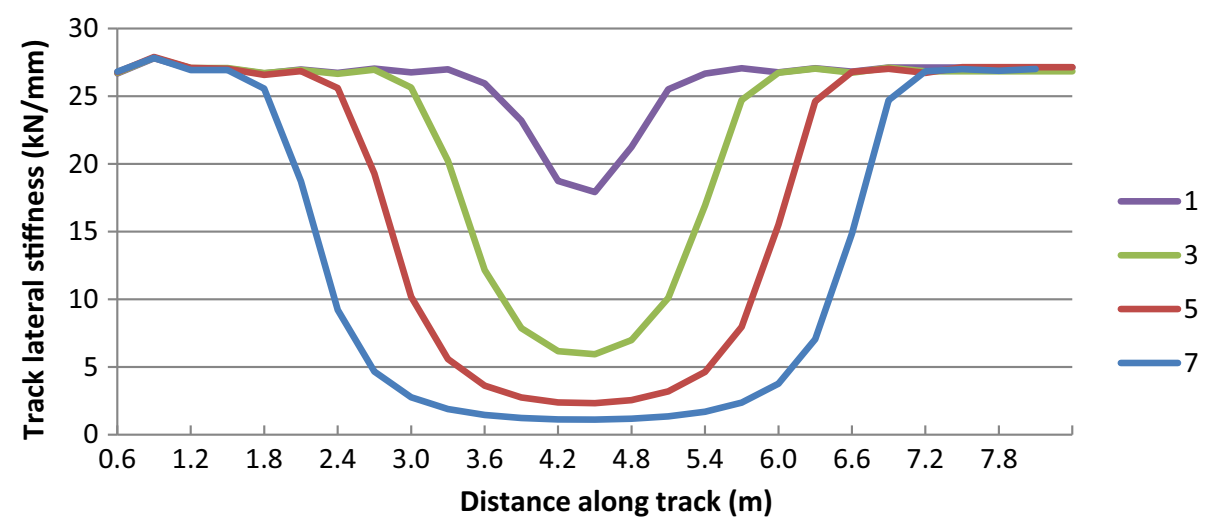

Fig. 5 Evolution of the track lateral stiffness along the track for different numbers of consecutive failed fasteners

fasteners fail. To do so, a unit load is applied on the centerline of the rail head in the vertical direction and another in the lateral direction, for calculating the displacements caused in the corresponding directions with the FEM model. From this displacements and knowing that loads are unit, the track vertical and lateral stiffness can be calculated applying Eq. (1). In Fig. 5, the variation of the track lateral stiffness along the track is represented for the different numbers of consecutive failed fasteners studied. As previously mentioned, failed fasteners are supposed to be in the center of the model in order to avoid the effect of the boundaries on the results and thus, the distance along track represented in Fig. 5 does not include the areas closer to the model extremes. The lateral stiffness approaches asymptotically the 0 value, since there is always a minimum of resistance caused by the rail lateral bending stiffness and the friction forces in the pad surfaces, the track lateral stiffness is not totally lost. Nevertheless, for the purposes of this study, it is assumed that the lateral stiffness is zero if more than 7 consecutive fasteners fail, since the remaining resistance is negligible if compared to the track with fasteners in perfect conditions.

The minimum values obtained at the point where fasteners fail are shown in Table 4 for different numbers of consecutive failed fasteners.

As the number of consecutive failed fasteners increases, the track lateral stiffness decreases and the vertical remains constant according to Fig. 5 and Table 4. When a fastener

Table 4 Minimum track vertical and lateral stiffness as a function of the number of consecutive failed fasteners

\begin{tabular}{lll}
\hline Number of failed fasteners & $k_{\mathrm{v}}(\mathrm{kN} / \mathrm{mm})$ & $k_{\mathrm{h}}(\mathrm{kN} / \mathrm{mm})$ \\
\hline 0 & 90 & 27.7 \\
1 & 90 & 17.5 \\
3 & 90 & 5.8 \\
5 & 90 & 2.1 \\
7 & 90 & 1.1 \\
\hline
\end{tabular}

fails, vibrations and rail movements may cause that closer fasteners have higher stresses than in normal conditions. This might lead to a progressive fastener failure until the track losses completely its lateral resistance. As evidenced by the FEM model, for the studied track, this situation occurs if more than 7 consecutive fasteners fail; in this case, it can be assumed that the track does not oppose any resistance to lateral forces and the stability of the vehicle might be compromised.

\section{Dynamic analysis of the vehicles in curved tracks}

The parameters of two studied curves, which also can be found in the real line, as well as the running speeds of the passenger and freight trains are shown in Table 5. Speeds have been specifically defined to induce that the passenger train negotiates the curves with cant deficit (exerting a greater force on the high rail as a consequence of the centrifuge acceleration), while the freight train circulates in the curve with cant excess. The publication [14] revealed, implicitly, that both the cant excess and deficiency cause high forces in the low and high rails, respectively, modifying the derailment coefficient. In order to assess the less favorable scenario, fasteners are supposed to fail in the high rail for the analysis of the passenger train and in the low rail for the analysis of the freight train.

Cant excess or deficiency can be quantified by means of uncompensated acceleration $(\gamma)$. This parameter represents the share of the total centrifuge acceleration which is not compensated by the track geometry in each case. Its value can be calculated by Eq. (3), in which $V$ is the vehicle speed, $R$ the curve radius, $h$ the cant, $g$ the acceleration of the gravity $\left(9.81 \mathrm{~m} / \mathrm{s}^{2}\right)$, and $d$ the track gage $(1,668 \mathrm{~mm})$ :

$\gamma=\frac{V^{2}}{R}-\frac{h}{d} g$. 
Table 5 Parameters and maximum train speeds of the studied curves

\begin{tabular}{lllll}
\hline Curve No. & Radius $(\mathrm{m})$ & Cant $(\mathrm{mm})$ & Passenger train speed $(\mathrm{km} / \mathrm{h})$ & Freight train speed $(\mathrm{km} / \mathrm{h})$ \\
\hline Curve 1 & 2,500 & 160 & 200 & 80 \\
Curve 2 & 1,000 & 100 & 125 & 80 \\
\hline
\end{tabular}

Table 6 Uncompensated acceleration $(\gamma)$ for the different studied cases (units: $\mathrm{m} / \mathrm{s}^{2}$ )

\begin{tabular}{lll}
\hline Curve no. & Passenger train & Freight train \\
\hline Curve 1 & 0.294 & -0.743 \\
Curve 2 & 0.618 & -0.09 \\
\hline
\end{tabular}

The results for the uncompensated acceleration in the different cases proposed in this study are presented in Table 6 . The higher uncompensated acceleration is, the higher centrifugal force results, pushing the train out of the track and causing greater forces in the wheel-rail contact.

\subsection{Analysis of the dynamic forces}

Firstly, the evolution of the vertical and lateral forces when the fasteners fail will be analyzed. For this purpose, the details obtained from the dynamic simulation in VAMPIRE for the case in which 7 fasteners fail are thoroughly studied since it is at this point when the track losses all its lateral resistance and the increase of the forces is more clearly appreciated. Moreover, it will be distinguished which part of these forces is exclusively due to the fasteners failure and not to the geometric conditions of the track and the vehicle. The development of the dynamic forces along the curve is shown in Fig. 6 for the passenger train and in Fig. 7 for the freight train. In the case of the passenger train, the results correspond to the fourth wheelset of the first vehicle, while in the freight train the results are obtained for the second wheelset of the third vehicle. These wheelsets have been found to be the closest to derailment in both curves studied. Results are shown along $200 \mathrm{~m}$ in the center of the curve, considering that failed fasteners begin at the point $x=2,000 \mathrm{~m}$.

From Figs. 6 and 7, it can be deduced that, in all cases, the peak in lateral forces is not produced exactly at the point where fasteners start to fail $(x=2,000 \mathrm{~m})$ but $25 \mathrm{~m}$ later for the passenger train and up to $40 \mathrm{~m}$ for the freight train. Before reaching this point, in which an abrupt change in dynamic forces occur, forces remain constant around a value which is proportional to the uncompensated acceleration caused by the cant excess or deficit of the vehicle in the curve (see Table 6). This effect can be explained by the fact that, as the train circulates on the failed-fastener stretch, no force opposes the lateral movement of the wheel-rail system; however, when the train leaves the
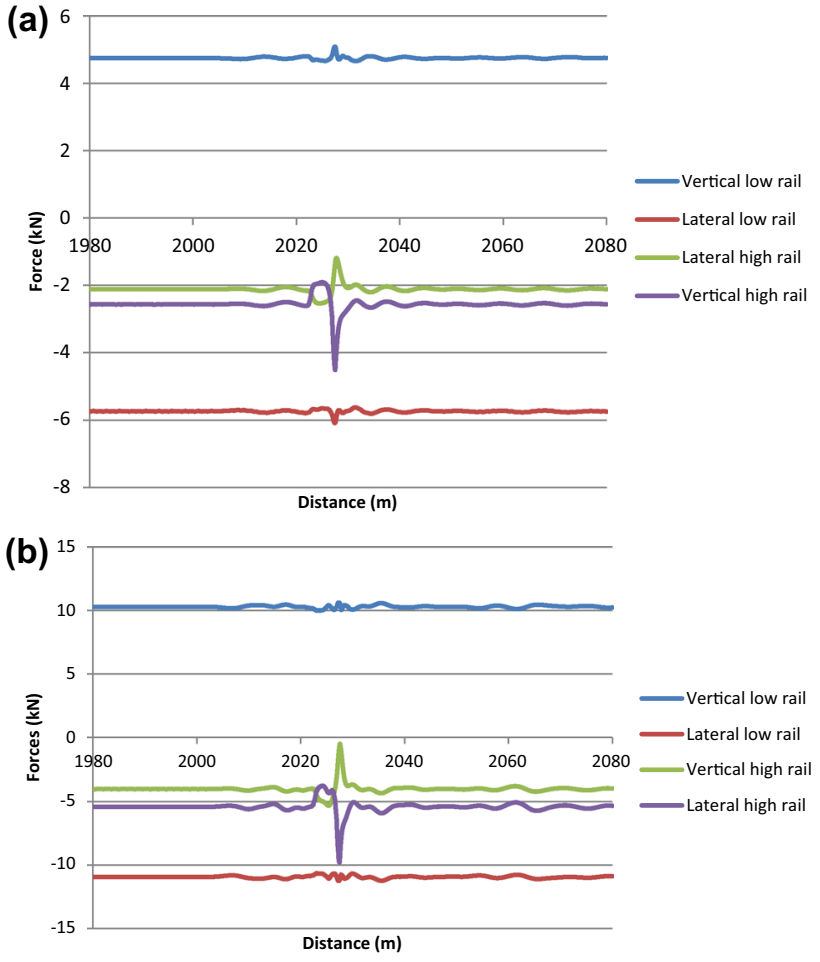

Fig. 6 Forces in Curve 1 (a) and in Curve 2 (b) for the passenger train when 7 consecutive fasteners fail

failed-fastener stretch, the track exerts a force which tries to reestablish the train direction and oppose the yaw movements that the vehicle is experiencing in the flawed stretch. This point is where great lateral forces appear in the graphs of Figs. 6 and 7.

Peaks of vertical forces appear at the same time that peaks of lateral forces do but are significantly lower. Furthermore, it can be also affirmed that vertical forces are proportional to the uncompensated acceleration and remain almost unaltered by the fasteners' failure.

Once studied in detail, the dynamic effects in the less favorable case, the evolution of lateral dynamic forces as a function of the number of failed fasteners up to the point in which the track losses its lateral resistance (i.e., with 7 consecutive failed fasteners) is presented in Fig. 8. Vertical dynamic forces are not included in this discussion because they remain almost unaffected by the lateral stiffness as seen above.

Results in Fig. 8 are coherent with the uncompensated accelerations calculated in Table 6 . The passenger train 

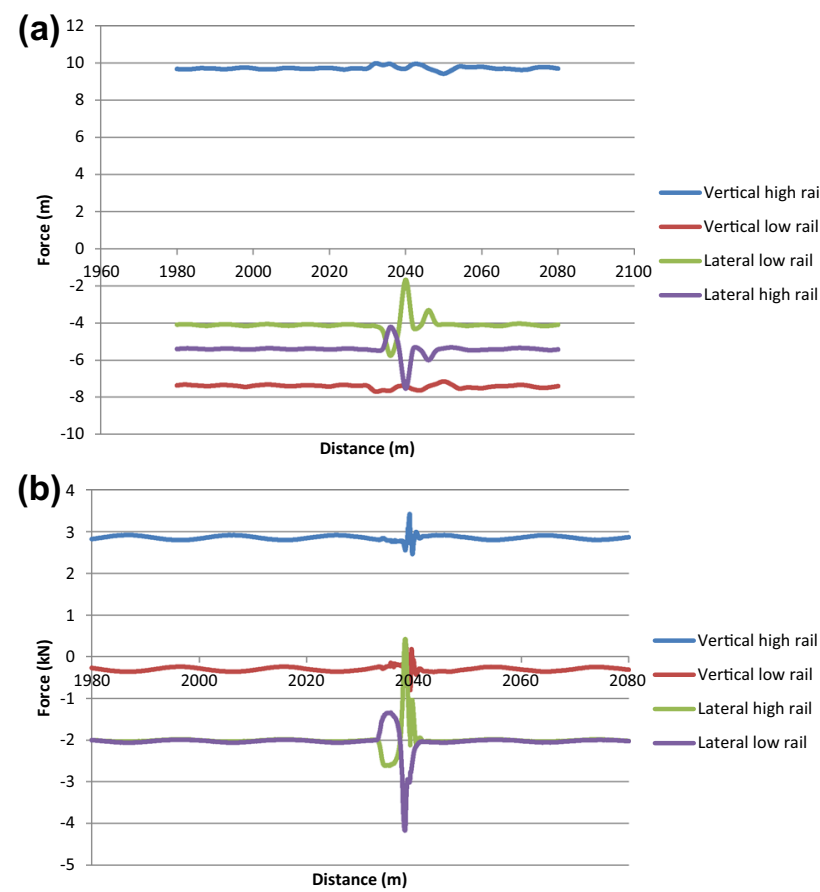

Fig. 7 Forces in Curve 1 (a) and in Curve 2 (b) for the freight train when 7 consecutive fasteners fail

transmits higher lateral forces in Curve 2 as a consequence of the greater uncompensated acceleration in this curve, while in the case of the freight train, the greater uncompensated acceleration appears in Curve 1 , resulting in higher forces associated to the fasteners' failure. In any case, lateral forces are under the maximum of $62 \mathrm{kN}$ fixed by the UIC (International Union of Railways) [24], which means that the momentary lack of track lateral stiffness caused by the fasteners' failure does not represent a serious danger for the stability of the track-vehicle system.

Additionally, the simultaneous failure of seven fasteners in the high and the low rail has been studied in the scenarios that resulted more prone to derailment: Curve 2 for the passenger train and Curve 1 for the freight train. Results in Fig. 9 reveal that the maximum dynamic forces

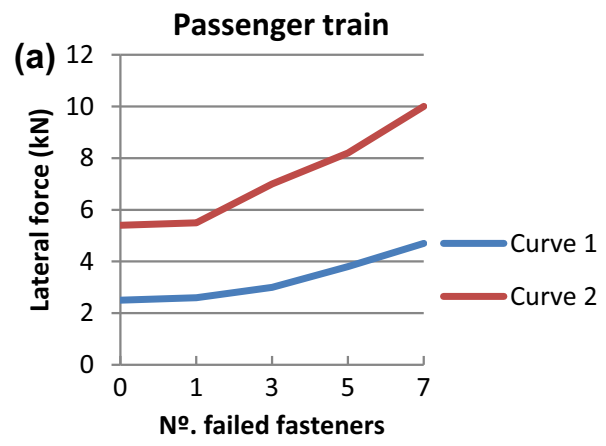

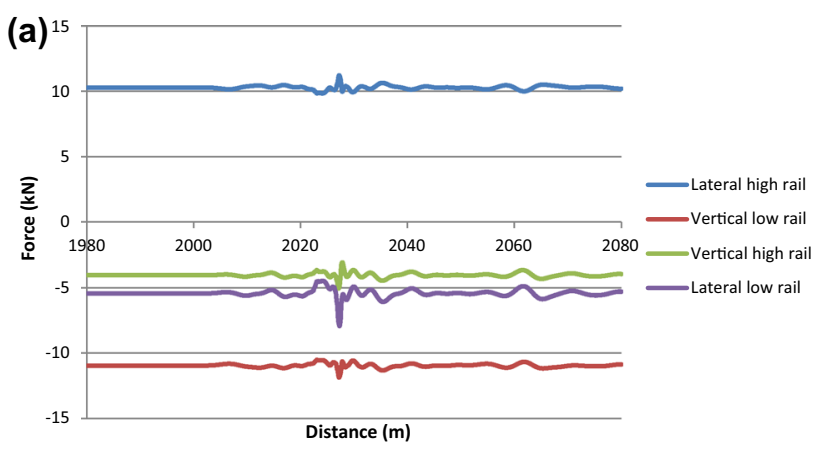

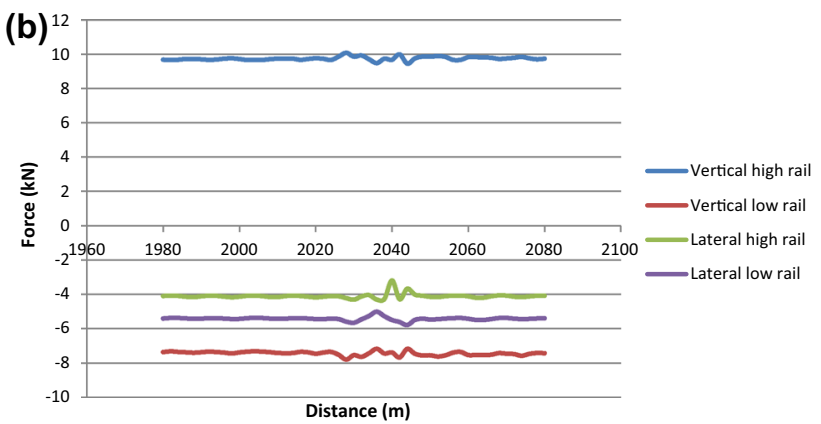

Fig. 9 Forces in Curve 2 for the passenger train (a) and in Curve 1 for the freight train (b) when 7 consecutive fasteners fail simultaneously in each rail

caused by the simultaneous failure of the fasteners in both rails are not significantly different from those obtained in Figs. 6 and 7, which were calculated supposing flawed fasteners in a single rail.

\subsection{Analysis of the derailment coefficient}

Derailment coefficient $D$ is defined as the ratio of the lateral force $L$ to the vertical force $V$. This coefficient is used to evaluate the risk of derailment of a railway vehicle by comparing its value with the so-called limit derailment coefficients, which depend on many factors according to the derailment mechanism considered in each case. For instance, the Nadal's criterion considers the flange climb and, therefore, the limit derailment coefficient depends on

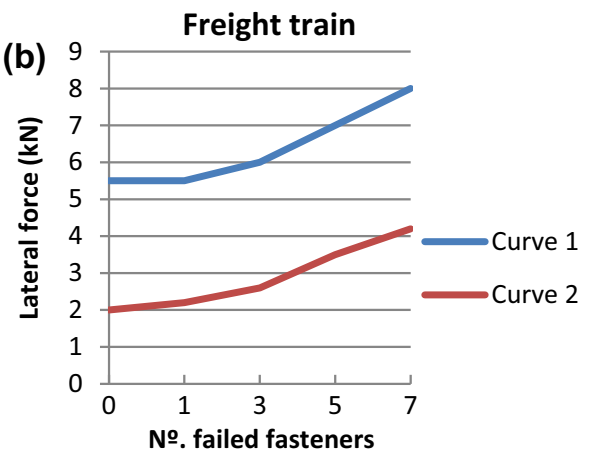

Fig. 8 Evolution of track lateral stiffness with the number of failed fasteners for passenger train (a) and freight train (b) 

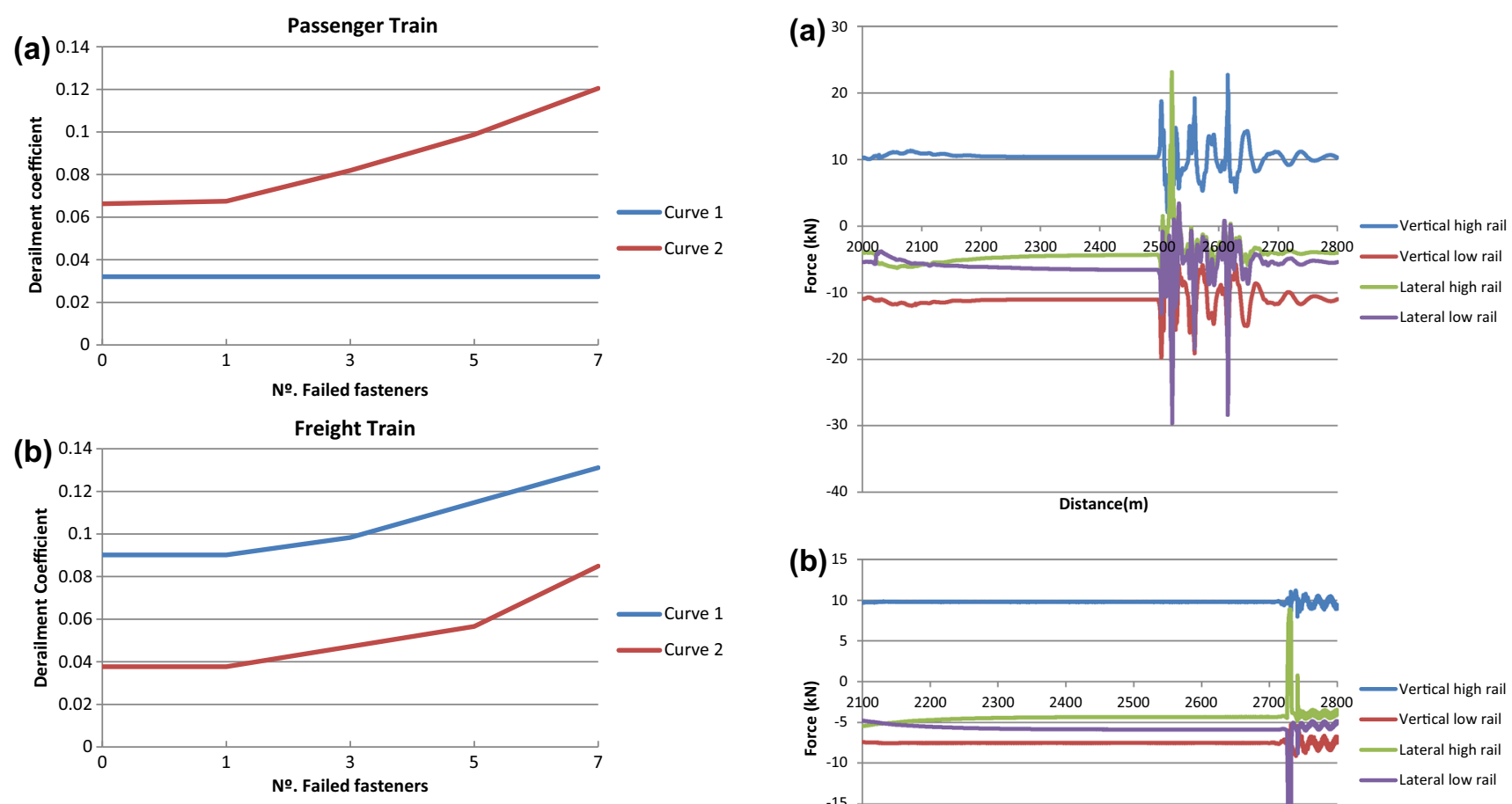

Fig. 10 Evolution of the derailment coefficient with the number of failed fasteners for passenger train (a) and freight train (b) in the studied scenarios

the friction of the wheel and the rail (See [25]). However, some studies consider the derailment by wheel lifting and consequently include in the calculation of the limit derailment coefficient lateral acceleration and axle forces [26].

The UIC leaflet 518 [27] sets the limit value for the limit derailment coefficient to 0.8 and specifies that this limit must not be exceeded along a length of $2 \mathrm{~m}$; from that moment, the vehicle stability might be compromised. Besides, the standard UNE-EN 14363 [28] establishes that the wheels with worn flanges may derail when the derailment coefficient is over 0.4 . Hence, the value of 0.4 will be set as the limit derailment coefficient in this study.

Figure 10 shows the value of the derailment coefficient in the studied scenarios, taking into account that the wheel derailment would be produced in the high rail for the passenger train and in the low rail for the freight train since both vehicles negotiate the curve with cant deficit and excess, respectively.

As depicted in Fig. 10, derailment coefficient remains far below the limit of 0.4 . For this reason, it can be concluded that there is not risk of derailment in the studied cases when 7 consecutive fasteners fail, although the track had lost the lateral resistance in this point.

However, if the number of failed fasteners is high enough and the track losses its lateral resistance along a certain distance, the derailment coefficient may exceed the

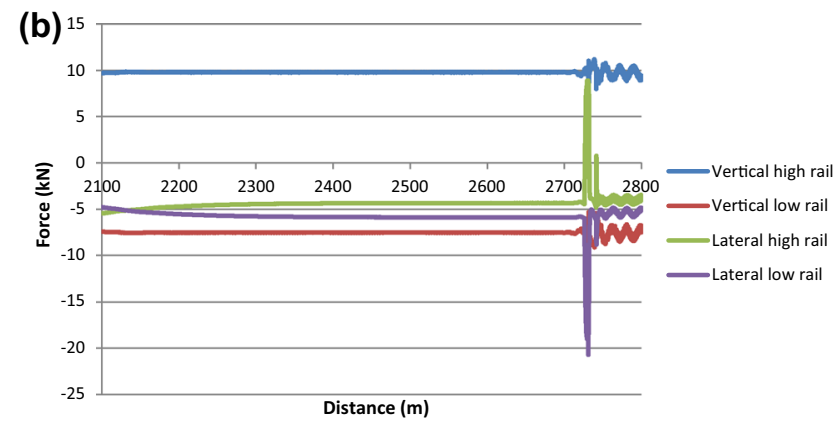

Fig. 11 Dynamic forces for the passenger train in Curve 2 (a) and for the freight train in Curve 1 (b) with failed fasteners along 500 and 750 $\mathrm{m}$, respectively

limit value, affecting the train safety. It has been proven that the limit value of 0.4 is surpassed for distances of failed fasteners of $500 \mathrm{~m}$ in the case of the passenger train negotiating Curve 2 and of $700 \mathrm{~m}$ in the case of the freight train negotiating Curve 1 . These cases are illustrated in Fig. 11, in which the reader can see how the maximum peak is produced again after the track recovers its lateral resistance and how the instability persists during the following meters. The evolution of the derailment coefficient along the curves is illustrated in Fig. 12 for these limit cases. As in the previous cases, the derailment risk appears in the low rail for the freight train and in the high rail for the passenger trains.

\section{Conclusions}

In this study, track vertical stiffness has been estimated from experimental results of track settlements using a FEM model. A new strategy to model the fastener as a clip and a compressive force calculated from the tightening torque has been explained, before studying the vehicle-track system dynamics in curves and the derailment risk. From the results obtained, it can be concluded that 

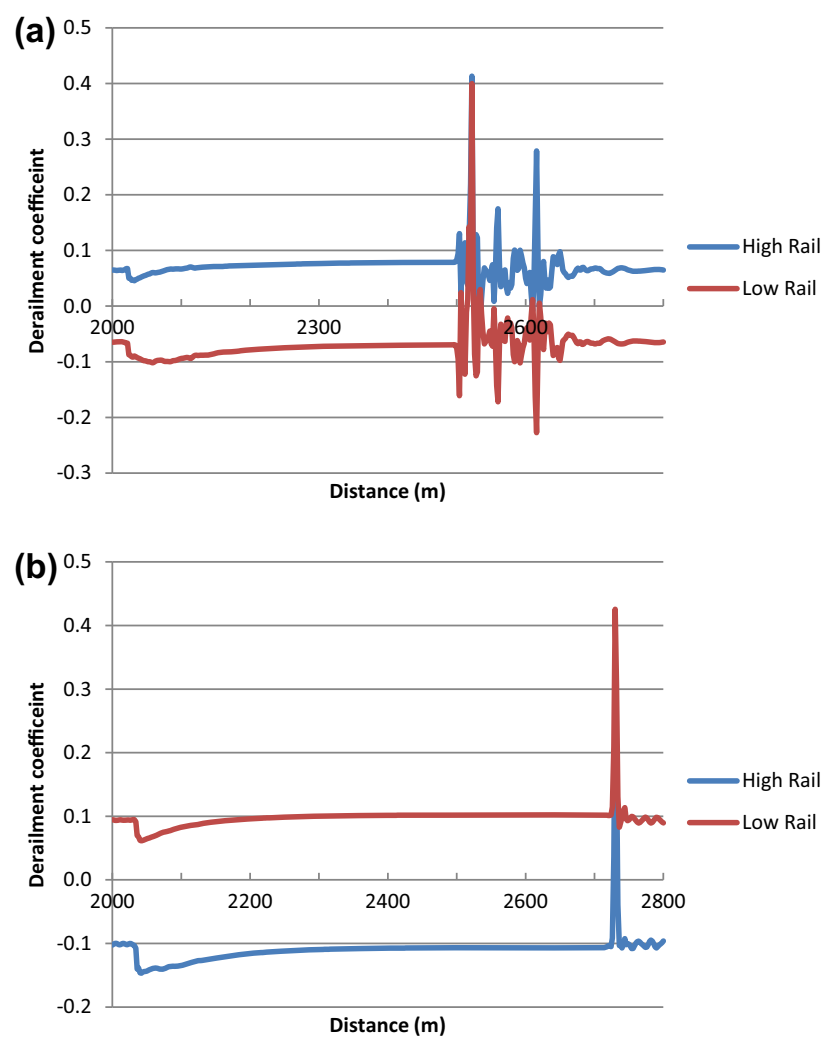

Fig. 12 Evolution of the derailment coefficient in the limit scenarios for passenger train (a) and freight train (b)

- The lateral forces are caused by the fasteners' failure, and their value is proportional to the uncompensated acceleration regardless of whether the vehicle negotiates the curve with cant excess or deficiency, according to [12], [13] and [14]. Vertical forces are not significantly influenced by the fasteners' failure.

- Although the studied track losses its lateral resistance when 7 consecutive fasteners fail, the vehicle stability is not compromised in this situation. However, if this situation of null lateral stiffness prevails along a certain distance, the vehicle may be in serious risk of derailment. In the studied examples, this critical distance was higher than $500 \mathrm{~m}$ for the two studied vehicles.

- The peak force due to the failed fasteners is not produced at the point where flawed fasteners are located but several meters after this point. An explanation to this phenomenon can be found in the fact that until the lateral stiffness is not totally recovered, there is no force opposing the yaw and lateral movements that the vehicle suffers on the stretch with flawed fasteners. It means that a potential derailment would not occur within the flawed zone but some meters beyond.

- The influence of fastener failure on the vehicle dynamics is similar when the flawed fasteners are located only in the rail which receives the extra load of the uncompensated acceleration and when the flawed fasteners are located in both rails simultaneously.

- The derailment coefficient increased with the distance along which fasteners fail. Even though lateral resistance is lost after 7 consecutive flawed fasteners, a higher number of failed fasteners must be considered in order to asses accurately the risk of derailment.

Open Access This article is distributed under the terms of the Creative Commons Attribution 4.0 International License (http:// creativecommons.org/licenses/by/4.0/), which permits unrestricted use, distribution, and reproduction in any medium, provided you give appropriate credit to the original author(s) and the source, provide a link to the Creative Commons license, and indicate if changes were made.

\section{References}

1. Iwnicki S (2006) Handbook of railway vehicle dynamics.CRC Press, Boca Ratón

2. Jin XS, Wen ZF, Wang KY, Zhou ZR, Liu QY, Li CH (2006) Three-dimensional train-track model for study of rail corrugation. J Sound Vib 293:830-855

3. Jin X, Wen Z, Xiao X (2007) A numerical method for prediction of curved rail wear. Multibody Sys Dyn 18:531-557

4. Li W, Xiao G, Wen Z, Xiao X, Jin X (2011) Plastic deformation of curved rail at rail weld caused by train-track dynamic interaction. Wear 271:311-318

5. Jin X, Wen Z (2008) Effect of discrete track support by sleepers on rail corrugation at a curved track. J Sound Vib 315:279-300

6. Di Gialleonardo E, Bruni S, True H (2014) Analysis of the nonlinear dynamics of a 2-axle freight wagon in curves. Veh Syst Dyn 52(1):125-141

7. Wang K, Liu P (2012) Lateral stability analysis of heavy-haul vehicle on curved track based on wheel/rail coupled dynamics. J Transp Technol 2:150-157

8. Kurzeck B, Hecht M (2010) Dynamic simulation of friction-induced vibrations in a light railway bogie while curving compared with measurement results. Veh Syst Dyn 48:121-138

9. Chen P, Gao L, Hao J (2007) Simulation study on parameters influencing wheel/rail wear in railway curve. China Railway Science 5

10. Sun Y, Cole C, Boyd P (2011) A numerical method using VAMPIRE modelling for prediction of turnout curve wheel-rail wear. Wear 271(1-2):482-491

11. Brabie D (2007) On derailment-worthiness in railway vehicle design. Analysis of vehicle features influencing derailment processes and consequences, PhD Thesis, Royal Institute of Technology, Stockholm

12. Matsumoto A, Sato Y, Ohno H, Shimizu M, Kurihara J, Saitou T, Michitsuji Y, Matsui R, Tanimoto M, Mizuno M (2014) Actual states of wheel/rail contact forces and friction on sharp curvescontinuous monitoring from in-service trains and numerical simulations. Wear 314:189-197

13. Wang L, Huang A, Liu G (2013) Analysis on curve negotiation ability of the rail vehicle based on SIMPACK. Adv Mater Res 721:551-555

14. Eom BG, Lee H (2010) Assessment of running safety of railway vehicles using multibody dynamics. Int $J$ Precis Eng Manuf 11(2):315-320 
15. Zhou L, Shen Z (2013) Dynamic analysis of a high-speed train operating on a curved track with failed fasteners. J Zhejiang Univ Sci A 14(6):447-458

16. Xiao X, Jin X, Wen Z (2007) Effect of disabled fastening systems and ballast on vehicle derailment. J Vib Acoust 129:217-229

17. Shi W, Cai C (2011) Influence of slab track fastener failure on track dynamic performance. In: Advances in environmental vibration-proceedings of the 5 th international symposium on environmental vibration, Chengdu, pp 686-692

18. Xiao X, Jin X, Deng Y, Zhou Z (2008) Effect of curved track support failure on vehicle derailment. Veh Syst Dyn 46(11):1029-1059

19. Zakeri J, Fakhari M, Mirfattahi B (2012) Lateral resistance of railway track with frictional sleepers. Proc Inst Civ Eng Transp 165(2):151-155

20. Gibert X, Patel V, Chellappa R (2015) Robust fastener detection for autonomous visual railway track inspection. In: IEEE Winter Conference on Applications of Computer Vision, Waikoloa Beach Hawai, pp 694-701

21. Thompson D, Hemsworth B, Vincent N (1996) Experimental validation of the TWINS prediction program for rolling noise, part 1: description of the model and method. J Sound Vib 193(1):123-135
22. Zakeri JA (2012) Lateral resistance of railway track. In: Perpinya DX (ed) Reliability and safety in railway. InTech Europe, Rijeka, pp 357-374

23. Kernes RG, Edwards JR, Dersh MS, Lange DA, Barkan CP (2011) Investigation of the dynamic frictional properties of a concrete crosstie rail seat and pad and its effect on rail seat deterioration (RSD). Transportation Research Board 91st annual meeting. Railtec, Chicago, Illinois

24. Carrascal-Vaquero I (2006) Optimization and analysis of the behavior of fastener systems for Spanish high-speed railways. $\mathrm{PhD}$ Thesis, University of Cantabria, Santander (In Spanish)

25. Sany J (1996) Another look at the single wheel derailment criteria. In: Proceedings of the IEEE/ASME Joint Railroad Conference, pp 17-22

26. Koo J, Oh H (2014) A new derailment coefficient considering dynamic and geometrical effects of a single wheelset. J Mech Sci Technol 28(9):3483-3498

27. UIC-Leaflet-518 (2009) Testing and approval of railway vehicles from the point of view of their dynamic behaviour-safety-track fatigue-ride quality. Railway Technical Publications, Paris

28. UNE-EN14363:2007 (2007) Railway applications-testing for the acceptance of running characteristics of railway vehicles-testing of running behaviour and stationary tests. AENOR, Madrid 